\title{
Regulation of Photosynthetic Electron Transport and Photoinhibition
}

\author{
Thomas Roach ${ }^{1}$ and Anja Krieger-Liszkay ${ }^{2, *}$
}

\begin{abstract}
${ }^{1}$ Institut für Botanik, Leopold-Franzens-Universität-Innsbruck, Sternwartestrasse 15, 6020 Innsbruck, Austria; ${ }^{2}$ Commissariat à l'Energie Atomique (CEA) Saclay, iBiTec-S, CNRS UMR 8221, Service de Bioénergétique, Biologie Structurale et Mécanisme, 91191 Gif-sur-Yvette Cedex, France
\end{abstract}

\begin{abstract}
Photosynthetic organisms and isolated photosystems are of interest for technical applications. In nature, photosynthetic electron transport has to work efficiently in contrasting environments such as shade and full sunlight at noon. Photosynthetic electron transport is regulated on many levels, starting with the energy transfer processes in antenna and ending with how reducing power is ultimately partitioned. This review starts by explaining how light energy can be dissipated or distributed by the various mechanisms of non-photochemical quenching, including thermal dissipation and state transitions, and how these processes influence photoinhibition of photosystem II (PSII). Furthermore, we will highlight the importance of the various alternative electron transport pathways, including the use of oxygen as the terminal electron acceptor and cyclic flow around photosystem I (PSI), the latter which seem particularly relevant to preventing photoinhibition of photosystem I. The control of excitation pressure in combination with the partitioning of reducing power influences the light-dependent formation of reactive oxygen species in PSII and in PSI, which may be a very important consideration to any artificial photosynthetic system or technical device using photosynthetic organisms.
\end{abstract}

Keywords: Electron transport, light stress, non-photochemical quenching, photoinhibition, photosynthesis, reactive oxygen species, regulation.

\section{INTRODUCTION}

In oxygenic photosynthesis light energy, with the help of light-harvesting antenna, is used to drive two specialized complexes called photosystem I (PSI) and photosystem II (PSII). The energy released from a captured photon triggers charge separation in PSI and PSII reaction centres, and subsequent electron transfer reactions, enabling electrons and protons to be taken from $\mathrm{H}_{2} \mathrm{O}$ and the release of $\mathrm{O}_{2}$. The released electrons are transported via a series of redox-active co-factors to reduce a final electron acceptor, such as $\mathrm{NADP}^{+}$. At the same time a proton gradient $(\Delta \mathrm{pH})$ is generated across the thylakoid membrane that provides, together with the electrochemical gradient $(\Delta \Psi)$, the proton motive force required for the synthesis of ATP. Charge separation creates a positive charge at the donor side of the photosystems, which is reduced by plastocyanin in PSI and by electrons from the water-splitting complex in PSII. While the absorption of light energy by antenna systems is highly efficient (i.e., extinction coefficient of chl: $\varepsilon$ : approx. $10^{5} \mathrm{M}^{-1}$ $\mathrm{cm}^{-1}$ ), and helped by a broad range in absorption wavelengths by chlorophyll $a, b$ and a number of carotenoid molecules, energy is lost during charge separation, stabilization and onward electron transfer. In photosynthesis, further energy is lost during $\mathrm{CO}_{2}$ fixation, especially under suboptimal conditions. In an optimal environmental setting, the maximum conversion of solar energy to biomass is estimated at $6 \%$, but only for the most efficient plants [1, 2].

*Address correspondence to this author at the CEA Saclay, iBiTec-S, Bât. 532, 91191 Gif-sur-Yvette Cedex, France;

Tel: +33 16908 1803; Fax: +33 16908 8717;

E-mail: anja.krieger-liszkay@cea.fr
The reaction centres of PSI and PSII convert photon energy into electrical potentials with very high efficiency $(80 \pm 15$ $\%$ and $45 \pm 10 \%$, respectively) [3] when measured on a microsecond timescale, making them highly attractive as potential photovoltaic devices $[4,5]$. On longer timescales, however, the energy conversion efficiency is largely reduced to about $40 \%$ for PSI [6]. Technical applications are increasingly exploiting the efficiency of photosynthesis for solidstate devices mimicking photovoltaic cells. Photo-electric currents have been achieved with immobilized chloroplasts [7], thylakoid membranes [8-10], PSII [11, 12] or PSI [1316] core complexes and isolated reaction centres [17-19]. One of the most promising current bio-photovoltaic without using elaborate or expensive surface chemistries is a PSI complex attached to a semiconductor, achieving a photocurrent density of $362 \mu \mathrm{A} / \mathrm{cm}^{2}$ and $0.5 \mathrm{~V}$ [15]. Purified complexes [20], photosynthetic membranes [21-24] or whole organisms [25-29] have also been placed on electrodes for assembling biosensors (for review see [30, 31]), mainly for the detection of pollutants, but also as components for future $\mathrm{H}_{2}$ production devices [32]. As PSI has a higher efficiency and is less prone to photoinhibion than PSII (see later), it could be more suitable for biomimetic devices (for recent reviews see [32-34]).

Natural photosynthesis is a highly regulated process. Several mechanisms help to protect the photosystems against light-induced damage (photoinhibition) when photon flux densities exceed the photosynthetic capacity. Moreover, the intensity when light becomes excess depends on the environment. Hence, in unfavourable conditions light saturation occurs at lower intensities (Fig. 1). Excess energy that cannot 
be used to drive photosynthesis enhances the production of reactive oxygen species (ROS) and induces photooxidative damage. Although some regulatory mechanisms may only be important in a living organism, energy dissipation and alternative electron pathways could be relevant for improving the stability of technical devices based on the use of whole photosynthetic organisms like unicellular algae or of isolated photosystems [35]. This review will cover the different levels that regulate photosynthesis in natural systems by using examples from higher plants and the model green alga Chlamydomonas reinhardtii. We start by covering the various pathways of light-induced production of ROS, major sources of ROS in plants (for reviews see [36-40]), and then cover how this relates to photoinhibition. The review continues with how excess energy can be dissipated to heat or distributed between the photosystems for protection, but also for influencing the production ratio of ATP:NADPH. Furthermore, we will describe the various electron transport pathways and highlight their importance, from linear to pseudocyclic flow (also called the Mehler reaction) and cyclic, which seems particularly relevant to photoinhibition of PSI. The control of excitation pressure in combination with the partitioning of different electron transport pathways influences the light-dependent formation of ROS, thus is paramount in controlling the stability and longevity of the photosynthetic apparatus.

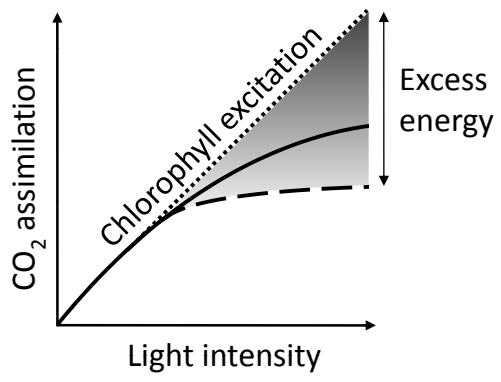

Fig. (1). The light response curve of $\mathrm{CO}_{2}$ fixation. With increasing absorbed quanta (dotted line), carbon assimilation eventually saturates and the difference between the two is excess energy. The level when photosynthesis saturates is lowered under unfavourable conditions, as represented by the dashed line.

\section{GENERATION OF REACTIVE OXYGEN SPECIES AND PHOTOINHIBITION}

Excitation of pigments and electron transfer reactions in an oxygen-rich environment inevitably leads to photooxidative damage. This is visible to the eye by a bleaching of the chlorophyll leading to pale green or even whitish leaves under extreme light conditions, especially when plants adapted to shade are suddenly exposed to high light intensities. Light-induced damage of the photosynthetic apparatus is caused by excessive production of ROS such as singlet oxygen $\left({ }^{1} \mathrm{O}_{2}\right)$, superoxide $\left(\mathrm{O}_{2}^{\circ-}\right)$, hydrogen peroxide $\left(\mathrm{H}_{2} \mathrm{O}_{2}\right)$ and hydroxyl radicals $\left(\mathrm{HO}^{\circ}\right)$ (Fig. 2).

Among the ROS, ${ }^{1} \mathrm{O}_{2}$ and $\mathrm{HO}^{\circ}$ are the most reactive species that are able to oxidize lipids, proteins and nucleic acids. Although ROS are important signalling molecules in photosynthetic organisms, high production rates saturate antioxidant defences, lead to oxidative damage and ultimately reduce growth and plant fitness. The up regulation of antioxi- dant defences is part of an acclimation of photosynthetic organisms to very high light intensities [41]. Moreover, in nonliving devices the production of ROS for signalling purposes is unnecessary, allowing ROS production to be minimised.
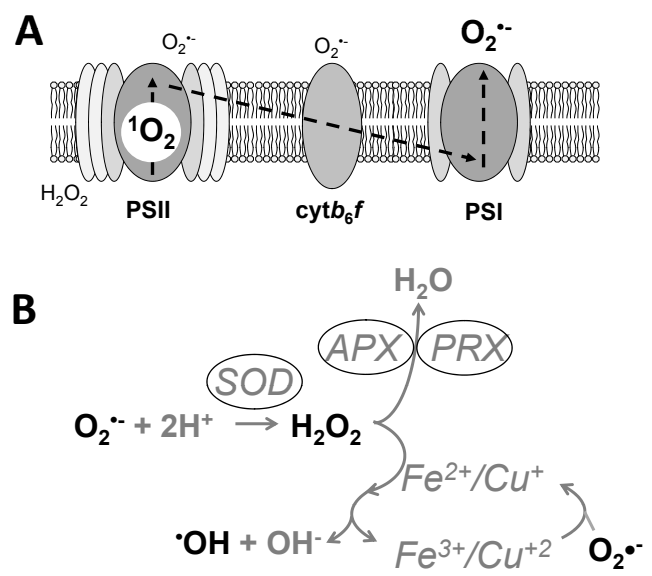

Fig. (2). Sites of reactive oxygen species (ROS) production at the thylakoid membrane. [A] Singlet oxygen $\left({ }^{1} \mathrm{O}_{2}\right)$ production occurs from charge recombination reactions in photosystem II (PSII), whereas superoxide $\left(\mathrm{O}_{2}{ }^{-}\right)$is predominantly produced by single electron reductions of $\mathrm{O}_{2}$ at the acceptor side of photosystem I (PSI). Other electron carriers, such as cytochrome $b_{6} f\left(\mathrm{Cyt} b_{6} f\right)$ may also produce negligible amounts of $\mathrm{O}_{2}{ }^{--}$or hydrogen peroxide $\left(\mathrm{H}_{2} \mathrm{O}_{2}\right)$. The dotted arrows represent electron flow. [B] The dismutation of $\mathrm{O}_{2}^{--}$to $\mathrm{H}_{2} \mathrm{O}_{2}$ is catalysed by superoxide dismutase (SOD), which in the chloroplast is broken down by ascorbate peroxidase (APX) and peroxiredoxins (PRX). In contact with $\mathrm{Fe}^{2+}$ or $\mathrm{Cu}^{+}$, $\mathrm{H}_{2} \mathrm{O}_{2}$ can produce the hydroxyl radical $\left(\mathrm{HO}^{\circ}\right)$ and $\mathrm{Fe}^{3+} / \mathrm{Cu}^{2+}$ can be recycled with $\mathrm{O}_{2}{ }^{\circ}$.

${ }^{1} \mathrm{O}_{2}$ is produced by the reaction of excited chlorophyll in its triplet state $\left({ }^{3} \mathrm{Chl}\right.$ ) with ${ }^{3} \mathrm{O}_{2}$ (molecular oxygen is in a triplet state in its ground state). In the reaction centre of PSII, ${ }^{3} \mathrm{Chl}$ is generated by charge recombination of the primary radical pair $\left(\mathrm{P}_{680^{+}} \mathrm{Phe}^{-}\right)$, with pheophytin (Phe) being the primary electron acceptor and P680 the primary chlorophyll electron donor. When light absorption exceeds the capacity of photosynthetic electron transport, the probability of ${ }^{1} \mathrm{O}_{2}$ generation increases. The pathway of charge recombination depends on the energetic of the electron acceptors of PSII (for details see [42, 43]). Charge recombination between the primary quinone electron acceptor $\left(\mathrm{Q}_{\mathrm{A}}\right)$ and $\mathrm{P} 680^{+}$can proceed via an indirect pathway and the repopulation of the primary radical pair or directly into the ground state of P680. The indirect pathway leads to the formation of ${ }^{3} \mathrm{Chl}$ and ${ }^{1} \mathrm{O}_{2}$ while the direct pathway is safe (for a more detailed description see [44]). A regulation mechanism has been described by which the yield of ${ }^{1} \mathrm{O}_{2}$ production is lowered in PSII with an inactive water-splitting complex. According to this mechanism, ${ }^{1} \mathrm{O}_{2}$ generation in PSII is controlled by a regulation of midpoint potential of $\mathrm{Q}_{\mathrm{A}}$. The yield of ${ }^{1} \mathrm{O}_{2}$ formation is lowered when $\mathrm{Q}_{\mathrm{A}}$ is in its so-called high potential form, i.e., when the midpoint redox potential of $\mathrm{Q}_{\mathrm{A}}$ is shifted to a more positive value. This shift in the midpoint potential allows a direct recombination of $\mathrm{P} 680^{+} \mathrm{Q}_{\mathrm{A}}{ }^{-}$to its ground state without repopulating the primary radical pair $\mathrm{P}_{68} 0^{+} \mathrm{Phe}^{-}[42$, $44,45]$. PSII centres with high potential $\mathrm{Q}_{\mathrm{A}}$ have been ob- 
served under different physiological conditions in vivo: 1) In green algae prior to photoactivation (the light-dependent assembly of the Mn cluster) [46], and 2) in leaves of higher plants under high light conditions [40]. The dependence of the amount of ${ }^{1} \mathrm{O}_{2}$ generation in PSII upon the midpoint potential $\mathrm{Q}_{\mathrm{A}}$ has been demonstrated by electron paramagnetic resonance (EPR) spectroscopy in vitro using a spin probe [47] and in vivo by a specific fluorescence dye in Chlamydomonas $[48,49]$. It has been shown that the yield of ${ }^{1} \mathrm{O}_{2}$ generation correlates with the loss of the $\mathrm{D} 1$ protein, one of the main subunits of the PSII reaction centre [50, 51]. Although chlorophyll-containing light hravesting complex (LHC) of photosystems contain many more chlorophylls, they are less susceptible to damage by ${ }^{1} \mathrm{O}_{2}$. In native systems, these antennas are well protected against ${ }^{1} \mathrm{O}_{2}$ formation by nearby carotenoids, including xanthophylls, which efficiently quench ${ }^{3} \mathrm{Chl}[52,53]$.

Photoinhibition and degradation of the D1 protein takes place over a large range of light intensities, although a net loss of PSII activity is only observed at high light intensities since the repair of PSII is very efficient in vivo [54]. However, at very low light intensities when the secondary PSII quinone electron acceptor $\left(\mathrm{Q}_{\mathrm{B}}\right)$ is only semi-reduced, photodamage and D1 loss can also take place. For example, PSII photoinhibition caused by charge recombination reactions and ${ }^{1} \mathrm{O}_{2}$ generation has been observed in green algae at very low light intensities [55] and after excitation of PSII in isolated thylakoid membranes by single turnover flashes [56, 57]. It is not only the midpoint potential of the redox couple $\mathrm{Q}_{\mathrm{A}} / \mathrm{Q}_{\mathrm{A}}{ }^{-}$that influences the probability of the non-radiative pathway of charge recombination, but also the midpoint potential of the redox couple Phe/Phe [58]. Interestingly, cyanobacteria have two genes for distinct D1 proteins, a main subunit of the PSII reaction centre, with different amino acids at position D1-130. Special D1E130 proteins are expressed only during high light conditions [59], and are thought to shift the redox potential of Phe to enhance charge recombination via the safe non-radiative pathways, thereby lowering the yield of ${ }^{1} \mathrm{O}_{2}$ generation [43]. Similar to the high light isoform of the D1 protein in cyanobacteria, a glutamate occupies the position D1-130 in all higher plants with known sequences. In Chlamydomonas, substitution of alanine at D1-251 of the $\mathrm{Q}_{\mathrm{B}}$ binding pocket to cysteine improved tolerance to cosmic radiation in space-flight and cell survival after returning to earth [60]. PSII can undergo posttranslational modifications associated to stress protection and repair. For example, the phosphorylation of the PSIIassociated chlorophyll-binding protein CP29 protects from cold-stress [61]. Moreover, the D1 subunit is under a circadian-regulated phosphorylation pattern [62] and requires dephosphorylation before it undergoes degradation [63]. Phosphorylation is also key to thylakoid membrane folding enabling access of repair enzymes [64] and the migration of photosystem antennas in state transitions, as discussed later. For recent detailed reviews on photosynthesis-related phosphorylation readers are directed towards [65] and [66].

Beside ${ }^{1} \mathrm{O}_{2}$ other ROS play an important role in lightinduced damage of the photosystems. Superoxide is mainly generated at the acceptor side of PSI in the so-called Mehler reaction $[67,68]$. In this reaction, $\mathrm{O}_{2}$ is reduced by ferredoxin or by the PSI iron-sulphur acceptor $\mathrm{F}_{\mathrm{x}}$. In algae and cyanobacteria reduction of $\mathrm{O}_{2}$ can be the dominant electron transport pathway [69], such as before the light-induced activation of the Calvin-Benson cycle [70], while in higher plants its importance as alternative electron sink is thought to be less important [71, 72]. It has been recently reported that gymnosperms have an increased capacity of the Mehler reaction (about $10 \%$ of the maximum electron flow) compared to angiosperms, but only during dark to light transition before the Calvin cycle is active [73]. In angiosperms it is thought that the importance of the Mehler reaction increases under stress conditions, such as drought, when the $\mathrm{CO}_{2}$ availability is limited by stomatal closure [71]. In addition it has been reported that the photoperiod plays a role in the partition between linear electron flow to $\mathrm{NADP}^{+}$and Mehler reaction [74]. Further investigations are needed to elucidate the physiological importance of the Mehler reaction, if and how it is regulated in vivo.

Besides being generated at the acceptor side of PSI, $\mathrm{O}_{2}{ }^{-}$ can also be produced in vitro at the level of the cytochrome $b_{6} f$ complex (cyt $b_{6} f$ ) [75] and at the acceptor side of PSII. In addition, the cytochrome $b 559$, an intrinsic protein subunit of PSII can act, depending on its redox potential as an oxygen reductase, as a superoxide reductase or as a superoxide oxidase [76]. However, the capacities of these pathways of $\mathrm{O}_{2}$ reduction seem to play only very minor roles in an intact, functional electron transport chain in thylakoid membranes.

A major source of photosynthesis-associated ROS is the $\mathrm{H}_{2} \mathrm{O}_{2}$ produced by photorespiration during the recycling of bi-products of the oxygenase activity of RubisCO [77]. This occurs outside the chloroplast in the peroxisome and will not be discussed here. However, $\mathrm{H}_{2} \mathrm{O}_{2}$ is generated in isolated chloroplasts, thylakoids and PSI or PSII preparations by the dismutation of $\mathrm{O}_{2}{ }^{-}$, either spontaneously or catalyzed by superoxide dismutase (SOD). Small amounts of $\mathrm{H}_{2} \mathrm{O}_{2}$ can also be generated directly by incomplete water splitting at the donor side of PSII as has been shown in vitro using isolated PSII membranes [78]. Furthermore, it can be formed by the reduction of $\mathrm{O}_{2}^{-}$by plastoquinol [79]. $\mathrm{H}_{2} \mathrm{O}_{2}$ itself is not that toxic, but in the presence of transition metals, such as $\mathrm{Fe}^{2+}$ or $\mathrm{Cu}^{+}$, it is converted to the highly reactive $\mathrm{HO}^{\circ}$ radical (Fig. 2). Apart from the Fenton reaction, $\mathrm{HO}^{\circ}$ may also be formed by the reduction of peroxide by metal centres coordinated to the proteins involved in electron transport.

In the intact chloroplasts, several enzymes are present that detoxify ROS. $\mathrm{O}_{2}{ }^{-}$is dismutated to $\mathrm{H}_{2} \mathrm{O}_{2}$ by SOD containing $\mathrm{Cu}$ and $\mathrm{Zn}(\mathrm{Cu} / \mathrm{Zn}-\mathrm{SOD})$ or $\mathrm{Fe}(\mathrm{Fe}-\mathrm{SOD})$ as a cofactor. $\mathrm{H}_{2} \mathrm{O}_{2}$ is mainly detoxified by ascorbate peroxidase (APX) [80] and by chloroplast-located peroxiredoxins (PRX) [81]. While APX activity requires ascorbate, PRX activity is dependent on re-reduction by thiol or thioredoxins. The ascorbate $(20-300 \mathrm{mM})$ and glutathione (GSH; 0.5 - $3.5 \mathrm{mM}$ ) content of the chloroplast $[82,83]$ is sufficiently high enough to enable a very efficient $\mathrm{H}_{2} \mathrm{O}_{2}$ detoxifying system [69]. Furthermore, thiols and thioredoxins are substrates for glutathione peroxidases and glutathione-s-transferases, which are important in detoxifying reactive lipid species formed by ${ }^{1} \mathrm{O}_{2}[84,85] .{ }^{1} \mathrm{O}_{2}$ can be scavenged by tocopherol, plastoquinone, carotenoids and by ascorbate [86-88]. Despite ascorbate, these scavengers are present in isolated systems and will help to protect the photosystems in the light. However, they have limited capacity because regeneration cannot take 
place and after a given time they become exhausted. The addition of catalase, a non-chloroplast located enzyme, increased the efficiency and stability of thylakoid bioelectrodes [8] confirming that $\mathrm{H}_{2} \mathrm{O}_{2}$ production can be an issue in artificial devices.

It is accepted by the majority of researchers that ROS directly damage photosystems with PSII being more vulnerable against oxidative damage than PSI. However, some researchers have suggested that the repair mechanism of the D1 protein is solely damaged by ROS, and not the PSII reaction centre itself (see Special Issue Physiologia Plantarum 2011 for the current debate). In vivo, the repair of PSII is so efficient that damage is only transitory [54]. Addition of methylviologen to isolated thylakoids, which enhances $\mathrm{O}_{2}{ }^{-}$ at the acceptor side of PSI, still led to greater inhibition of PSII than PSI [89], showing that PSII is much more susceptible to ROS-induced damage than PSI, even when the site of production is located at PSI. It is intriguing that the D1 reaction centre at the heart of PSII photoinhibiton has remained highly susceptible to photo-damage in all oxygenic photosynthetic organisms and at all light intensities. Despite the apparent wastefulness of PSII photoinhibition, it can also be regarded as a regulatory mechanism of photosynthesis, since it lowers linear electron transport under excess light conditions and may thereby prevent photoinhibition of PSI [90]. Photoinhibition of PSI has a higher impact on the performance of the photosynthetic apparatus since no efficient repair cycle exists [90].

\section{REGULATION OF LIGHT HARVESTING}

What makes photosynthesis remarkable is that it efficiently functions under highly fluctuating photon flux densities, under environmental constraints and in accordance with the metabolic demands of the organism. Photoregulation is coordinated at multiple levels; At the pigment and protein levels via energy-transfer processes involving carotenoids and chlorophylls, at the membrane and cellular levels with supramolecular organization in the thylakoid membrane, at the cellular level by chloroplast relocation and at the organism level including heliotropism of plants and phototaxis of microorganisms. Within the thylakoid membrane, light harvesting complexes facilitate in capturing light energy and its transfer to the reaction centres for charge separation. This partitioning between light harvesting and reaction centres provides an opportunity in regulating how much and to which reaction centre energy is delivered to, thereby preventing excessive excitation, ROS production and the costs associated with photoinhibitory damage. Collectively, this plethora of regulatory mechanisms controlling light energy in intact organism is known as non-photochemical quenching (NPQ), due to their detection by measurements of chlorophyll fluorescence quenching that are distinct from photochemical quenching (i.e., use of the captured light energy in chemical reactions such as $\mathrm{CO}_{2}$ fixation). For a complete guide on chlorophyll measurements of photosynthetic efficiency readers are directed to [91]. There are three components to NPQ; 1) dissipation of excess light energy in antenna to heat before it reaches the reaction centre $(\mathrm{qE}), 2$ ) state transitions where light adsorption is balanced between the photosystems by movement of antenna (qT) and 3) 'short term' photoinhibition of PSII (qI), which recovers slower than $\mathrm{qE}$ or $\mathrm{qT}[92,93]$. As discussed below, $\mathrm{qT}$ and $\mathrm{qE}$ are governed by the plastoquinone (PQ) pool redox state and the thylakoid proton-motive force, respectively, which makes photosynthesis a highly efficient self-regulated process. For a comprehensive review on how photosynthetic organisms respond to excess light see [94].

\section{THE QE COMPONENT OF NPQ}

The $\mathrm{qE}$ component of NPQ, where light energy is dissipated before reaching the reaction centres, has been assigned to a synergistic action of the $\Delta \mathrm{pH}$ since a low $\mathrm{pH}$ in the thylakoid lumen activates the xanthophylls cycle and leads to protonation of luminal residues of proteins such as PsbS and LhcSR3 that reduce energy transfer from the antenna to the PSII reaction centre (Fig. 3). In the xanthophyll cycle, the low $\mathrm{pH}$ activates a de-epoxidation of violaxanthin to zeaxanthin and requires minutes to hours to become fully activated [95, 96], but zeaxanthin can temporarily remain active after the loss of the $\Delta \mathrm{pH}$ [93]. Lutein is another xanthophyll implicated in $\mathrm{qE}$ and protection from high light in both Arabidopsis and Chlamydomonas [52, 97]. Another $\Delta \mathrm{pH}$-dependent component of $\mathrm{qE}$ is protonation of light harvesting complexes (LHC) and an LHC-type protein, which rapidly induces NPQ within seconds [98]. In higher plants this trans-membrane LHC-type protein is PsbS [99], whereas in green algae (e.g., Chlamydomonas) it is LhcSR3 [100]. Differences between the proteins include PsbS being constitutively expressed and not binding pigments, whereas LhcSR3 is highly inducible by excess light and binds chlorophyll and carotenoids [101]. Moreover, the mechanism of LhcSR3 is less dynamic than PsbS and leads to quenching even in low light, which is perhaps why LhcSR3 is a high light-inducible protein [101, 102]. Evidence suggests the switch from LhcSR3 to PsbS happened when organisms colonised the land and was likely associated with the extra stresses associated with terrestrial life [103]. Mosses can contain both proteins as has been shown for Physcomitrella patens [104] and Rhytidium rugusum (data not shown). Regardless, mutants of Arabidopsis or Chlamydomonas deficient in either PsbS or LhcSR3, both referred to as $n p q 4$, have retarded abilities to dissipate excess energy and show sensitivity to high or naturally fluctuating light [100, 105]. The aggregation of LHC II trimers and detachment from PSII is also observed during $\mathrm{qE}$ induction [106]. Due to the influence of $\Delta \mathrm{pH}$ on $\mathrm{qE}$, a regulation of ATP synthase activity, which uses the $\Delta \mathrm{pH}$ to produce ATP also influences NPQ [107], possibly through thioredoxin-mediated redox control, but this has yet to be confirmed [108]. Recommended introductory reviews to $\mathrm{qE}$ are $[102,109]$ for model plants and [110] in other plants, but also see $[52,111]$ for further debate.

We have recently shown in vitro using Arabidopsis chloroplasts that ${ }^{1} \mathrm{O}_{2}$ production is influenced by the presence or absence of PsbS-dependent NPQ capacity [112]. Other markers of ${ }^{1} \mathrm{O}_{2}$ production are the oxidation of $\beta$-carotene inside the reaction centre and of prenyllipids such as $\alpha$ tocopherol and plastoquinone [86]. It has also been reported that $\beta$-carotene is more oxidised in Arabidopsis npq4 than wild-type following excess light stress, confirming qE protects against reaction centre damage by ${ }^{1} \mathrm{O}_{2}$ [113]. In addition to $\mathrm{qE}$, other mechanisms of energy dissipation operate in specialised situations. For example, a light- and nigericin- 
insensitive activation of the xanthophyll cycle has been shown in a desiccation-tolerant fern and in lichens [114]. Moreover, an induction of non-radiative charge recombinations in PSII (see above) occurs in cyanobacterial desert crusts in response to high light, avoiding the formation of ${ }^{3} \mathrm{Chl}$ and associated ${ }^{1} \mathrm{O}_{2}$ [115]. Although NPQ is essential to the contribution of desiccation tolerance [116], the contribution of the xanthophyll cycle to NPQ is not always supported, indicating that other mechanisms, such as chlorophyll cations that are very efficient quenchers [117], are responsible for the desiccation-induced NPQ [118]. However, xanthophylls may play other roles in protection from excess light due to their efficient ability to scavenge ROS, such as zeaxanthin protecting from ${ }^{1} \mathrm{O}_{2}[119,120]$ and neoxanthin from $\mathrm{O}_{2}{ }^{-}$[121]. In cyanobacteria, a different type of $\mathrm{qE}$ has been described which relies on the light-induced conversion of the Orange-Carotenoid-Protein (OCP) to its active red form that quenches fluorescence (for review see [122]).

\section{qE component of NPQ}
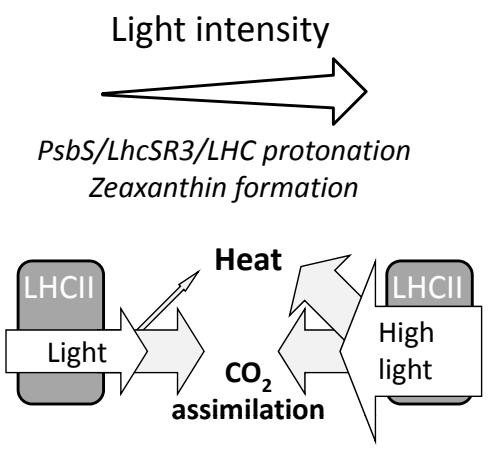

Fig. (3). Mitigating excess light via the $\mathrm{qE}$ component of nonphotochemical quenching. With increasing light intensities, the light-dependent production of a proton gradient across the thylakoid membrane induces two mechanisms that dissipate excess light energy to heat before it reaches the photosystem II reaction centre. Acidification of the lumen 1) enhances the enzymatic conversion of violaxanthin to antheraxanthin and zeaxanthin, and 2) protonates key residues of light harvesting complex II and PsbS (vascular plants) or LhcSR3 (green algae), which together participate in the dissipation of excess energy at the level of the PSII antenna preventing excess light from causing damage.

\section{THE QT COMPONENT OF NPQ}

Another light-inducible response, the so-called state transitions, influences excitation delivery to the photosystems. Light Harvesting Complex II (LHCII) can migrate to change the energy deliverance to PSII or PSI. Moreover, the movement of LHCII away from PSII relieves excitation pressure [123]. The migration of LHCII is under governance of the plastoquinone pool redox state, and therefore, the relative activities of PSII and PSI. Under high PSII activity and a reduced plastoquinone pool, plastoquinol binds to the Qo site of the cyt $b_{6} f$, which activates protein kinase STN7 to phosphorylate LHCII [124]. This is a pre-requisite for its movement to PSI and the induction of 'state 2' (Fig. 4). A more oxidised plastoquinone pool leads to the dissociation of plastoquinol from the Qo site of cyt $b_{6} f$, thereby deactivating the kinase and activating a phosphatase (as reviewed by [65]).
Consequently LHCII migrates back to PSII, referred to as 'state 1'. State transitions play a minor role in higher plants while they are highly important in green algae. In Arabidopsis, where only up to $15-20 \%$ of LHCII can be mobilised $[124,125]$, state transitions are important in acclimating to changing light intensities [126]. However, in Chlamydomonas $70-80 \%$ of can disassociates from PSII [127], but only $20 \%$ associates to PSI [127, 165]. It had been accepted in the literature for a long time that in Chlamydomonas the transition from state 1 to 2 is accompanied by a switch from linear to cyclic electron flow [128]. However, it has recently been demonstrated that this is not necessarily the case [129]. Although both state transitions and cyclic electron flow are induced by reducing conditions, the migration of LHCII to PSI is not a prerequisite for the induction of cyclic electron flow [129].

\section{qT component of NPQ}

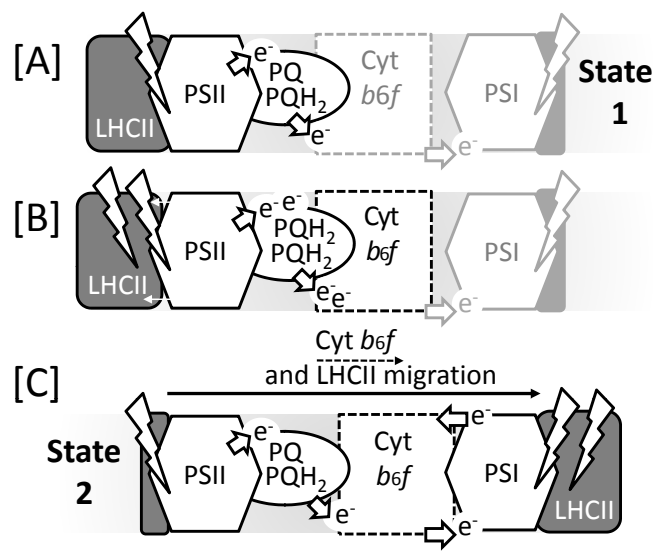

Fig. (4). Balancing light absorption by the photosystems via state transitions poised by the redox state of the plastoquinone pool. [A] Under moderate light, the redox state of the plastoquinone pool $\left(\mathrm{PQ} / \mathrm{PQH}_{2}\right)$ remains largely oxidised allowing linear electron flow, and the majority of light harvesting complex II (LHCII) is at PSII (state 1). [B] If PSII becomes over-excited relative to PSI, the PQ pool becomes over-reduced, favouring the binding of $\mathrm{PQH}_{2}$ to the Qo site of the cytochrome $b_{6} f$ complex $\left(\operatorname{cyt} b_{6} f\right)$, which induces a kinase to phosphorylate LHCII and the movable part of LHCII migrates to PSI. [C] The migration of LHCII to PSI (state 2) reduces excitation pressure at PSII lowering linear electron transport so that the PQ pool becomes re-oxidised.

The activation of high light responses are upregulated at different times and at different intensities depending upon the organism, presumably to address the different demands and adjustments. The fasted responses are $\mathrm{qE}$ (first minutes upon exposure to high light, followed by state transitions (qT) and finally leading to photoinhibition of PSII (qI). Although each mechanism has unique functions they also possess overlapping protective roles.

\section{REGULATION OF THE ELECTRON TRANSPORT CHAIN}

Beside the regulation of the amount and distribution of light energy to the reaction centres, the activity of the electron transport chain can be down regulated at different sites. The size of the $\Delta \mathrm{pH}$ is the most important component that 
not only controls $\mathrm{qE}$ (see above), but also regulates electron transport at the level of the cyt $b_{6} f$ and at the donor side of PSII. A decreased luminal $\mathrm{pH}$ limits electron transport by slowing the activity of the cyt $b_{6} f$, a regulation mechanism called "photosynthetic control" $[130,131]$. The lumen $\mathrm{pH}$ in Arabidopsis leaves under ambient $\mathrm{CO}_{2}$ was estimated to range from approximately $\mathrm{pH} 7.5$ to 6.5 under weak and saturating light, respectively [132]. These moderate $\mathrm{pH}$ values in the lumen allow regulation at the antenna level via $\mathrm{qE}$ and via electron transport through the cyt $b_{6} f$, as well as preventing acid-induced damages. The $\mathrm{pH}$ value for zeaxanthin accumulation and PsbS protonation was estimated to be about 6.8 [132]. When net ATP synthesis is zero, the $\mathrm{pH}$ in the lumen can decrease as low as pH 5.2 (for review see [130], a $\mathrm{pH}$ at which the water-splitting activity and the reduction kinetics of $\mathrm{P} 680^{+}$start to be slowed down [133]. Below $\mathrm{pH} 5.5, \mathrm{Ca}^{2+}$, an obligatory co-factor of the watersplitting complex is reversibly removed, evoking a shift of $\mathrm{Q}_{\mathrm{A}}$ to the high potential form [134] and protecting PSII against ${ }^{1} \mathrm{O}_{2}$ generation (see above).

Beside processes that are regulated by the luminal $\mathrm{pH}$, alternative pathways of photosynthetic electron transport can release the pressure from the electron transport chain and prevent photoinhibtion. Under conditions of limiting light and no limitation on the electron acceptor side (i.e., sufficient $\mathrm{CO}_{2}$ ), linear electron transport is dominating and electrons released from splitting $\mathrm{H}_{2} \mathrm{O}$ in PSII are used by PSI to reduce electron acceptors such as $\mathrm{NADP}^{+}$. As electron acceptors become limited (i.e., low $\mathrm{CO}_{2}$ that limits NADPH oxidation for carbon assimilation), pseudocyclic electron flow / Mehler reaction (where $\mathrm{O}_{2}$ is the electron acceptor) and cyclic electron flow are increasingly able to compete for reducing power (Fig. 5). In cyclic electron flow the reducing power is not from PSII, but instead recycled back from PSI into the plastoquinone pool and via cyt $b_{6} f$. This occurs directly via ferredoxin and other proteins, such as PGR5 [135] and PGRL1 [136, 137], or via $\mathrm{NAD}(\mathrm{P}) \mathrm{H}$ dehydrogenases $(\mathrm{NDH})$ [138]. As the reinvested reducing power of cyclic electron flow passes through the Q-cycle of $\operatorname{cyt} b_{6} f$, the accompanied proton transport from stroma to lumen facilitates the formation of $\Delta \mathrm{pH}$, and hence, ATP production. For photosynthetic organisms switching between cyclic and noncyclic pathways provides a degree of flexibility in the ratio of ATP and NAPDH production to meet metabolic needs $[139,140]$. This is particularly important in ATP-expensive photosynthesis, such as CAM plants and in the bundle sheath cells of $\mathrm{C}_{4}$ plants, which both require a higher ATP:NADPH ratio for $\mathrm{CO}_{2}$ fixation than $\mathrm{C}_{3}$ photosynthesis. Furthermore, cyclic flow is enhanced when $\mathrm{CO}_{2}$ becomes limiting in both higher plants [141] and Chlamydomonas, the latter which has a high ATP demand under $\mathrm{CO}_{2}$ limitation because $\mathrm{CO}_{2}$ concentrating mechanisms operate at the expense of ATP [142]. Cyclic electron flow is clearly linked to stress, but the exact regulatory mechanism that switches it on is still unknown. A joint PSI-cyt $b_{6} f$ supercomplex for cyclic electron flow has been demonstrated biochemically to be formed in Chlamydomonas [129, 143], but not yet in higher plants. The $\mathrm{NAD}(\mathrm{P}) \mathrm{H}$ dehydrogenase $(\mathrm{NDH})$ route in Chlamydomonas is achieved by a monomeric protein called Nda2 [144], while in higher plants it is achieved by the NDH complex [145, 146]. Both can operate in the dark with non-photosynthetic supplies of $\mathrm{NAD}(\mathrm{P}) \mathrm{H}$. In Arabidopsis, at least, both the PGR5/PGRL1-dependent and the NDH-dependent cyclic pathways seem to be under redox regulation by thioredoxin m4 [147], while the PSI-cyt $b_{6} f$ supercomplex is $\mathrm{Ca}^{2+}$ dependent in Chlamydomonas [136].

As discussed above, cyclic electron transport is enhanced to support the production of a $\Delta \mathrm{pH}$ under conditions that limit carbon assimilation, including environmental stress. Thus it allows ATP generation without the net formation of reductants, such as reduced Ferredoxin or NADPH. The exclusion of linear electron flow also limits the Mehler reaction and $\mathrm{O}_{2}{ }^{-}$generation. Moreover, cyclic electron flow protects against photodamage of PSI since it keeps the acceptor side oxidized [90, 112, 135, 148, 149].

In addition to partitioning between linear electron flow, cyclic flow and Mehler reaction (Fig. 5), the plastid terminal oxidase (PTOX), which directly oxidises plastoquinol while reducing $\mathrm{O}_{2}$ to $\mathrm{H}_{2} \mathrm{O}$, has been proposed to act as a safety valve and to avoid photo-oxidative damage [150]. PTOX activity may also enhance the formation of a $\Delta \mathrm{pH}$, as demonstrated in marine organisms that survive in iron-depleted waters. Here, the cost of building iron-rich PSI is very high, but organisms can operate with PSII activity alone [151]. In alpine plants the level of PTOX protein is elevated, which may be linked to their ability to tolerate harsh conditions like very high irradiation at low temperatures [150, 152]. In agreement with this, PTOX levels are increased in plants exposed to extreme temperatures $[153,154]$ or to high salinity [155]. In Chlamydomas two isoforms of PTOX exist, PTOX and PTOX2. PTOX2 has been shown to keep the PQ pool oxidized in the dark [156]. However, in other model plants such as Arabidopsis thaliana, Nicotiana tabacum and Solanum lycopersicum grown under standard conditions, the role of PTOX in mature leaves is less clear. Overexpression of PTOX did not protect plants from photoinhibition [157] but actually enhanced it in some circumstances [158, 159]. Recent evidence indicates that PTOX rather modulates the balance between linear and cyclic flow than acting as a safety valve [160] since the capacity of electron flow via PTOX has been measured to be very limited in S. lycopersicum leaves [157]. Further investigations are needed to show the importance of PTOX as a safety valve under stress conditions.

In summary, the competition for absorbed quanta by alternative electron flows becomes important when the electron acceptor $\mathrm{NADP}^{+}$is limited. These electron flows include cyclic flow around PSI, the Mehler reaction and PTOX activity. Not only does this enable metabolic adjustment through regulating ATP:NADPH ratios, but also releases reducing pressure off the electron transport chain, lowering incidences of charge recombination and preventing ${ }^{1} \mathrm{O}_{2}$ production (see above). Hence, the incorporation of a regulatory mechanism to prevent over-reduction of charge carriers could also be attractive to artificial systems that may suffer damage under high loads.

\section{COST-BENEFIT RATIO OF REGULATORY MECHANISMS}

An obvious cost of photoregulatory processes is the loss in efficiency in photosynthetic yield. A delay in recovery of 
NPQ from the residual presence of zeaxanthin after high light treatment [93] may have high costs in carbon assimilation of agricultural plants [161]. In the non-native setting of agriculture that strives for maximum growth rates, the protection afforded by NPQ may well be, at times, too conservative. Therefore, opportunities for genetically manipulating light harvesting mechanisms for optimising yields may exist [162]. However, photoregulation prevents photoinhibition, which itself is costly in energetics and resources for repairing damaged reaction centres as well as in the photosynthesis forgone during repair (reviewed by [163]). Other protective expenses to photosynthetic organisms are the investment in antioxidants, such as ascorbate, that require complex biosynthetic pathways and reductants with other enzymes to recycle their activity. Therefore, the cost-benefit ratio of photoregulation versus photoinhibition is extremely complex, especially considering an ecological setting with unpredictable resource availability. As mentioned above, photoinhibition itself is a regulatory process of biological photosystems that can rapidly repair themselves. This brings into question the perhaps impossible task of increasing the longevity of isolated reaction centres in biomimetic systems, but the incorporation of exogenous antioxidants can help [8].

\section{Electron transport pathways}

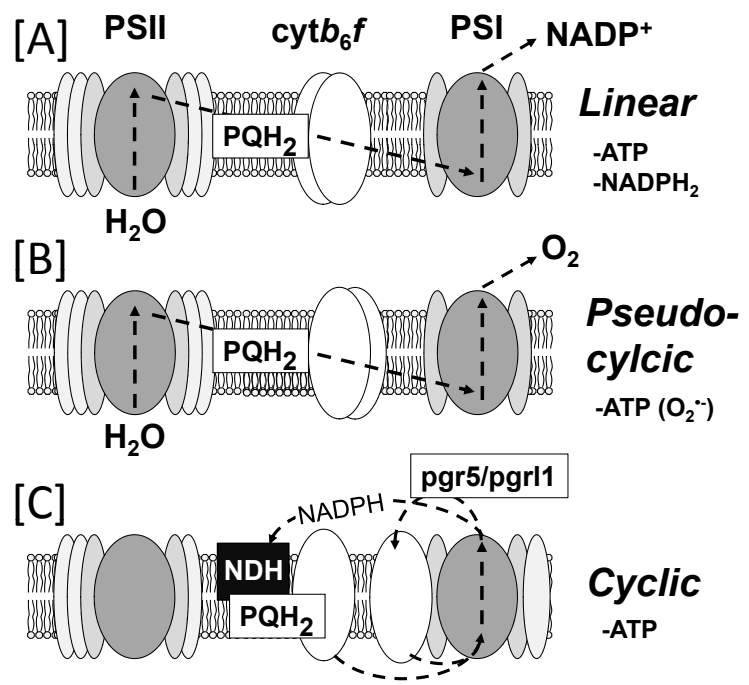

Fig. (5). Photosynthetic electron transport pathways. In linear electron flow [A] electrons released by water-splitting in photosystem II (PSII) reduce plastoquinone to plastoquinol $\left(\mathrm{PQH}_{2}\right)$, which migrates to the cytochrome $b_{6} f$ complex (cyt $b_{6} f$ ). Plastoquinol is oxidized by the cyt $b_{a} f$ and protons are released into the thylakoid lumen. Electrons are transported to plastocyanin (PC), which is the electron donor to photosystem I (PSI). At the acceptor side of PSI electrons are donated to $\mathrm{NADP}^{+}$. Alternatively, PSI can reduce $\mathrm{O}_{2}$ producing $\mathrm{O}_{2}{ }^{--}$(Mehler reaction or pseudocyclic flow) [B]. In cyclic electron flow [C] the reducing power from PSI is re-invested back into the electron transport chain via NADPH dehydrogenase (NDH), which reduces the plastoquinone pool, or via a pgr5/pgrl1 protein complex to cyt $b_{6} f$. All electron flows permit the generation of a thylakoid proton gradient for the generation of ATP, whereas only linear flow produces NADPH/H for carbon assimilation.

\section{USE OF REGULATORY MECHANISMS FOR TECH- NICAL EXPLOITATION}

The question arises as to what we can learn from the regulatory mechanisms of natural photosynthesis for using photosynthetic machinery in technical applications. First, one has to distinguish between technical applications that are either based on exploiting whole organisms as biosensors or using isolated complexes enriched with photosynthetic complexes. Inhibition of the photosynthetic electron transport in whole organisms is easily detectable by monitoring chlorophyll fluorescence and is used to detect heavy metal or herbicide pollution in water. Recent exploits using laser printing have achieved greater contact of electrodes with whole cells [164] or thylakoids [23], increasing efficiency of charge transfer and sensitivity of biosensors to the $\mathrm{nM}$ range [23, 25]. In an intact organism all natural regulatory mechanism are present and can be activated depending on the environmental conditions. To allow a long-term use of a biosensor based on intact organisms it has to be ensured that enough nutrients and $\mathrm{CO}_{2}$ are available and that waste is removed when intact organisms are embedded into a matrix for the technical application.

Regarding isolated systems, PSII complexes or PSIIenriched membrane fragments have already been tested as sensors to detect herbicides. Instead of using active PSII, with the highly vulnerable water-splitting complex, it may be interesting to use PSII with an inactivated donor side. Inactivation of the donor side leads to the shift of the midpoint potential of $\mathrm{Q}_{\mathrm{A}}$ to the high potential form as described above. PSII with high potential $\mathrm{Q}_{\mathrm{A}}$ is protected against damage by ${ }^{1} \mathrm{O}_{2}$. Herbicides bind efficiently to these modified PSII and herbicide binding could be detected by either measuring thermoluminescence or herbicide-induced changes in the decay kinetics of chlorophyll fluorescence. Isolated photosynthetic systems may well be devoid of metabolic control required in whole organisms in responding to changes in the environments like fluctuating light, but in an outside environment they will still be subjected to highly variable conditions of temperature and light intensity, affecting efficiency and performance. Therefore, when isolated thylakoid membranes or isolated PSI preparations will be used in a technical device, it may be useful to add a safety valve in analogy to the PTOX or the Mehler reaction present in the natural system. This safety valve should only operate when PSI (or both photosystems in case of thylakoids) becomes saturated. To design such a safety valve, a better understanding of the regulation of the Mehler reaction and of PTOX are first needed before reasonable suggestion can be made based on physiologically relevant protection mechanisms. As the field of bio-sensors and transducers is only in its infancy, we can expect great advances when technological advances are coupled with an enhanced understanding of photosynthesis and its control.

\section{CONFLICT OF INTEREST}

The authors confirm that this article content has no conflicts of interest.

\section{ACKNOWLEDGEMENTS}

We would like to thank José Ignacio García-Plazaola, University of the Basque Country, Spain, and Kathleen 
Feilke, CEA Saclay, for critical reading of the manuscript. TR was supported by EU FP7 Marie Curie Initial Training Network HARVEST (FP7 project no. 238017). This publication is supported by Grant of COST Action TD1102. COST (European Cooperation in Science and Technology) is Europe's longest-running intergovernmental framework for cooperation in science and technology funding cooperative scientific projects called 'COST Actions'. With a successful history of implementing scientific networking projects for over 40 years, COST offers scientists the opportunity to embark upon bottom-up, multidisciplinary and collaborative networks across all science and technology domains. For more information about COST, please visit www.cost.eu.

\section{REFERENCES}

[1] Zhu, X.-G.; Long, S.P.; Ort, D.R. What is the maximum efficiency with which photosynthesis can convert solar energy into biomass? Curr. Opin. Biotechnol., 2008, 19, 153-159.

[2] Ort, D.R.; Melis, A. Optimizing antenna size to maximize photosynthetic efficiency. Plant Physiol., 2011, 155, 79-85.

[3] Boichenko, V.A.; Hou, J.M.; Mauzerall, D. Thermodynamics of electron transfer in oxygenic photosynthetic reaction centers: volume change, enthalpy, and entropy of electron-transfer reactions in the intact cells of the cyanobacterium Synechocystis PCC 6803. Biochemistry, 2001, 40, 7126-7132.

[4] Faunce, T.A.; Lubitz, W.; Rutherford, A.W.; MacFarlane, D.; Moore, G.F.; Yang, P.; Nocera, D.G.; Moore, T.A.; Gregory, D.H.; Fukuzumi, S.; Yoon, K.B.; Armstrong, F.A.; Wasielewski, M.R.; Styring, S. Energy and environment policy case for a global project on artificial photosynthesis. Energ. Environ. Sci., 2013, 6, 695-698.

[5] Giardi, M.T.; Pace, E. Photosynthetic proteins for technological applications. Trends Biotechnol., 2005, 23, 257-263.

[6] Cha, Y.; Mauzerall, D. Energy storage of linear and cyclic electron flows in photosynthesis. Plant Physiol., 1991, 100, 1869-1877.

[7] Bhardwaj, R.; Pan, R.L.; Gross, E.L. Solar energy conversion by chloroplast photoelectrochemical cells. Nature, 1981, 289, 396398.

[8] Sjoholm, K.H.; Rasmussen, M.; Minteer, S.D. Bio-Solar Cells Incorporating Catalase for Stabilization of Thylakoid Bioelectrodes during Direct Photoelectrocatalysis. ECS Electrochemistry Letters, 2012, 1 , G7-G9.

[9] Rasmussen, M.; Minteer, S.D. Investigating the mechanism of thylakoid direct electron transfer for photocurrent generation. Electrochemical Society 224th Meeting, 2013, 2464.

[10] Rasmussen, M.; Shrier, A.; Minteer, S.D. High performance thylakoid bio-solar cell using laccase enzymatic biocathodes. Phys. Chem. Chem. Phys., 2013, 15, 9062.

[11] Vittadello, M.; Gorbunov, M.Y.; Mastrogiovanni, D.T.; Wielunski, L.S.; Garfunkel, E.L.; Guerrero, F.; Kirilovsky, D.; Sugiura, M.; Rutherford, A.W.; Safari, A.; Falkowski, P.G. Photoelectron generation by photosystem II core complexes tethered to gold surfaces. ChemSusChem, 2010, 3, 471-475.

[12] Kato, M.; Cardona, T.; Rutherford, A.W.; Reisner, E. Photoelectrochemical water oxidation with photosystem II integrated in a mesoporous indium-tin oxide electrode. $J$. Am. Chem. Soc., 2012, 134, 8332-8335.

[13] Yehezkeli, O.; Tel-Vered, R.; Michaeli, D.; Nechushtai, R.; Willner, I. Photosystem I (PSI)/Photosystem II (PSII)-Based PhotoBioelectrochemical Cells Revealing Directional Generation of Photocurrents. Small, 2013, 9(17), 2970-2978.

[14] Terasaki, N.; Yamamoto, N.; Tamada, K.; Hattori, M.; Hiraga, T.; Tohri, A.; Sato, I.; Iwai, M.; Iwai, M.; Taguchi, S.; Enami, I.; Inoue, Y.; Yamanoi, Y.; Yonezawa, T.; Mizuno, K.; Murata, M.; Nishihara, H.; Yoneyama, S.; Minakata, M.; Ohmori, T.; Sakai, M.; Fujii, M. Bio-photosensor: Cyanobacterial photosystem I coupled with transistor via molecular wire. Biochim. Biophys. Acta, 2007, 1767, 653-659.

[15] Mershin, A.; Matsumoto, K.; Kaiser, L.; Yu, D.; Vaughn, M.; Nazeeruddin, M.K.; Bruce, B.D.; Graetzel, M.; Zhang, S. Selfassembled photosystem-I biophotovoltaics on nanostructured $\mathrm{TiO}_{2}$ and ZnO. Scientific Reports, 2012, 2, 234.
[16] Carmeli, I.; Frolov, L.; Carmeli, C.; Richter, S. Photovoltaic activity of photosystem I-based self-assembled monolayer. J. Am. Chem. Soc., 2007, 129, 12352-12353.

[17] Lukashev, E.P.; Nadtochenko, V.A.; Permenova, E.P.; Sarkisov, O.M.; Rubin, A.B. Electron phototransfer between photosynthetic reaction centers of the bacteria Rhodobacter sphaeroides and semiconductor mesoporous $\mathrm{tiO}_{2}$ films. Dokl. Biochem. Biophys., 2007, 415, 211-216.

[18] Das, R.; Kiley, P.J.; Segal, M.; Norville, J.; Yu, A.A.; Wang, L.; Trammell, S.A.; Reddick, L.E.; Kumar, R.; Stellacci, F.; Lebedev, N.; Schnur, J.; Bruce, B.D.; Zhang, S.; Baldo, M. Integration of photosynthetic protein molecular complexes in solid-state electronic devices. Nano Letters, 2004, 4, 1079-1083.

[19] Trammell, S.A.; Spano, A.; Price, R.; Lebedev, N. Effect of protein orientation on electron transfer between photosynthetic reaction centers and carbon electrodes. Biosens. Bioelectron., 2006, 21, 1023-1028.

[20] Bhalla, V.; Zazubovich, V. Self-assembly and sensor response of photosynthetic reaction centers on screen-printed electrodes. Analytica Chimica Acta, 2011, 707, 184-190.

[21] Ventrella, A.; Catucci, L.; Placido, T.; Longobardi, F.; Agostiano, A. Biomaterials based on photosynthetic membranes as potential sensors for herbicides. Biosens. Bioelectron., 2011, 26, 4747-4752.

[22] Rasmussen, M.; Minteer, S.D. Self-powered herbicide biosensor utilizing thylakoid membranes. Anal. Methods, 2013, 5, 1140.

[23] Breton, F.; Euzet, P.; Piletsky, S. A.; Giardi, M.T.; Rouillon, R. Integration of photosynthetic biosensor with molecularly imprinted polymer-based solid phase extraction cartridge. Analytica Chimica Acta, 2006, 569, 50-57.

[24] Touloupakis, E.; Boutopoulos, C.; Buonasera, K.; Zergioti, I.; Giardi, M.T. A photosynthetic biosensor with enhanced electron transfer generation realized by laser printing technology. Anal. Bioanal. Chem., 2012, 402, 3237-3244.

[25] Ferro, Y.; Perullini, M.; Jobbagy, M.; Bilmes, S.A., Durrieu, C. Development of a biosensor for environmental monitoring based on microalgae immobilized in silica hydrogels. Sensors, 2012, 12, 16879-16891.

[26] Lambreva, M.D.; Giardi, M.T.; Rambaldi, I.; Antonacci, A.; Pastorelli, S.; Bertalan, I.; Husu, I.; Johanningmeier, U.; Rea, G. A powerful molecular engineering tool provided efficient Chlamydomonas mutants as bio-sensing elements for herbicides detection. PloS One, 2013, 8, e61851.

[27] Husu, I.; Rodio, G.; Touloupakis, E.; Lambreva, M.D.; Buonasera, K.; Litescu, S.C.; Giardi, M.T.; Rea, G. Insights into photoelectrochemical sensing of herbicides driven by Chlamydomonas reinhardtii cells. Sensor. Actuat. B-Chem., 2013, 185, 321-330.

[28] Zamaleeva, A.I.; Sharipova, I.R.; Shamagsumova, R. V.; Ivanov, A.N.; Evtugyn, G.A.; Ishmuchametova, D.G.; Fakhrullin, R.F. A whole-cell amperometric herbicide biosensor based on magnetically functionalised microalgae and screen-printed electrodes. Anal. Methods, 2011, 3, 509.

[29] Shitanda, I.; Takamatsu, S.; Watanabe, K.; Itagaki, M. Amperometric screen-printed algal biosensor with flow injection analysis system for detection of environmental toxic compounds. Electrochimica Acta, 2009, 54, 4933-4936.

[30] Buonasera, K.; Lambreva, M.; Rea, G.; Touloupakis, E., Giardi, M.T. Technological applications of chlorophyll a fluorescence for the assessment of environmental pollutants. Anal. Bioanal. Chem., 2011, 401, 1139-1151.

[31] Doval, D.A.; Areephong, J.; Bang, E.-K.; Bertone, L.; Charbonnaz, P.; Fin, A.; Lin, N.-T.; Lista, M.; Matile, S.; Montenegro, J.; Orentas, E.; Sakai, N.; Tran, D.-H.; Jentzsch, A.V. Recent progress with functional biosupramolecular systems. Langmuir, 2011, 27, 9696-9705.

[32] Mazor, Y.; Toporik, H.; Nelson, N. Temperature-sensitive PSII and promiscuous PSI as a possible solution for sustainable photosynthetic hydrogen production. Biochim. Biophys. Acta, 2012, $1817,1122-1126$.

[33] Lubner, C.E.; Grimme, R.; Bryant, D.A.; Golbeck, J.H. Wiring photosystem I for direct solar hydrogen production. Biochemistry, 2010, 49, 404-414.

[34] Kargul, J.; Janna Olmos, J.D.; Krupnik, T. Structure and function of photosystem I and its application in biomimetic solar-to-fuel systems. J. Plant Physiol., 2012, 169, 1639-1653. 
[35] Seibert, M.; Picorel, R.; Rubin, A.B.; Connolly, J.S. Spectral, photophysical, and stability properties of isolated photosystem II reaction center. Plant Physiol., 1988, 87, 303-306.

[36] Asada, K. Production and scavenging of reactive oxygen species in chloroplasts and their functions. Plant Physiol., 2006, 141, 391396.

[37] Fischer, B.B.; Hideg, É.; Krieger-Liszkay, A. Production, detection; and signaling of singlet oxygen in photosynthetic organisms. Antioxid. Redox Signal., 2013, 18, 2145-2162.

[38] Foyer, C.H.; Noctor, G. Redox regulation in photosynthetic organisms: signaling, acclimation, and practical implications. Antioxid. Redox Signal., 2009, 11, 861-905.

[39] Keren, N.; Krieger-Liszkay, A. Photoinhibition: molecular mechanisms and physiological significance. Physiol. Plant., 2011, 142, 1-5.

[40] Krieger-Liszkay, A.; Fufezan, C.; Trebst, A. Singlet oxygen production in photosystem II and related protection mechanism. Photosynth. Res., 2008, 98, 551-564.

[41] Förster, B.; Osmond, C.B.; Pogson, B.J. Improved survival of very high light and oxidative stress is conferred by spontaneous gain-offunction mutations in Chlamydomonas. Biochim. Biophys. Acta, 2005, 1709, 45-57.

[42] Krieger-Liszkay, A.; Rutherford, A.W. Influence of herbicide binding on the redox potential of the quinone acceptor in photosystem II: relevance to photodamage and phytotoxicity. Biochemistry, 1998, 37, 17339-17344.

[43] Vass, I. Molecular mechanisms of photodamage in the Photosystem II complex. Biochim. Biophys. Acta, 2012, 1817, 209-217.

[44] Rutherford, A.W.; Krieger-Liszkay, A. Herbicide-induced oxidative stress in photosystem II. Trends Biochem. Sci., 2001, 26, 648-653.

[45] Fufezan, C.; Drepper, F.; Juhnke, H.D.; Lancaster, C.R.D.; Un, S.; Rutherford, A.W.; Krieger-Liszkay, A. Herbicide-induced changes in charge recombination and redox potential of $\mathrm{Q}(\mathrm{A})$ in the T4 mutant of Blastochloris viridis. Biochemistry, 2005, 44, 5931-5939.

[46] Johnson, G.N.; Rutherford, A.W.; Krieger, A. A change in the midpoint potential of the quinone QA in Photosystem II associated with photoactivation of oxygen evolution. Biochim. Biophys. Acta, 1995, 1229, 202-207.

[47] Fufezan, C.; Gross, C.M.; Sjödin, M.; Rutherford, A.W.; KriegerLiszkay, A.; Kirilovsky, D. Influence of the redox potential of the primary quinone electron acceptor on photoinhibition in photosystem II. J. Biol. Chem., 2007, 282, 12492-12502.

[48] Fischer, B.B.; Krieger-Liszkay, A.; Hideg, E.; Snyrychová, I.; Wiesendanger, M.; Eggen, R.I.L. Role of singlet oxygen in chloroplast to nucleus retrograde signaling in Chlamydomonas reinhardtii. FEBS Lett., 2007, 581, 5555-5560.

[49] Roach, T.; Sedoud, A.; Krieger-Liszkay, A. Acetate in mixotrophic growth medium affects photosystem II in Chlamydomonas reinhardtii and protects against photoinhibition. Biochim. Biophys. Acta, 2013, 1827, 1183-1190.

[50] Hideg, E.; Spetea, C.; Vass, I. Singlet oxygen production in thylakoid membranes during photoinhibition as detected by EPR spectroscopy. Photosynth. Res., 1994, 39, 191-199.

[51] Fischer, B.B.; Eggen, R.I.L.; Trebst, A.; Krieger-Liszkay, A. The glutathione peroxidase homologous gene Gpxh in Chlamydomonas reinhardtii is upregulated by singlet oxygen produced in photosystem II. Planta, 2006, 223, 583-590.

[52] Jahns, P.; Holzwarth, A.R. The role of the xanthophyll cycle and of lutein in photoprotection of photosystem II. Biochim. Biophys. Acta, 2012, 1817, 182-193.

[53] Böhm, F.; Edge, R.; Truscott, T.G. Interactions of dietary carotenoids with singlet oxygen 102 and free radicals: potential effects for human health. Acta Biochimica Polonica, 2012, 59, 27 30 .

[54] Edelman, M.; Mattoo, A.K. D1-protein dynamics in photosystem II: the lingering enigma. Photosynth. Res., 2008, 98, 609-620.

[55] Keren, N.; Gong, H.; Ohad, I. Oscillations of reaction center II-D1 protein degradation in vivo induced by repetitive light flashes Correlation between the level of RCII-QB- and protein degradation in low light. J. Biol. Chem., 1995, 270, 806-814.

[56] Szilárd, A.; Sass, L.; Hideg, E.; Vass, I. Photoinactivation of photosystem II by flashing light. Photosynth. Res., 2005, 84, 15-20.

[57] Keren, N.; Berg, A.; Van Kan, P.J.M.; Levanon, H.; Ohad, I. Mechanism of photosystem II photoinactivation and D1 protein degradation at low light: The role of back electron flow. Proc. Natl. Acad. Sci. U.S.A., 1997, 94, 1579-1584.

[58] Cser, K.; Vass, I. Radiative and non-radiative charge recombination pathways in Photosystem II studied by thermoluminescence and chlorophyll fluorescence in the cyanobacterium Synechocystis 6803. Biochim. Biophys. Acta, 2007, 1767, 233-243.

[59] Kós, P.B.; Deák, Z.; Cheregi, O.; Vass, I. Differential regulation of psbA and psbD gene expression, and the role of the different D1 protein copies in the cyanobacterium Thermosynechococcus elongatus BP-1. Biochim. Biophys. Acta, 2008, 1777, 74-83.

[60] Giardi, M.T.; Rea, G.; Lambreva, M.D.; Antonacci, A.; Pastorelli, S.; Bertalan, I.; Johanningmeier, U.; Mattoo, A.K. Mutations of photosystem II D1 protein that empower efficient phenotypes of Chlamydomonas reinhardtii under extreme environment in space. PloS One, 2013, 8, e64352.

[61] Bergantino, E.; Dainese, P., Cerovic; Z., Sechi, S.; Bassi, R. A Post-translational Modification of the Photosystem II Subunit CP29 Protects Maize from Cold Stress. J. Biol. Chem., 1995, 270, 84748481.

[62] Booij-James, I.S.; Swegle, W.M.; Edelman, M.; Mattoo, A.K. Phosphorylation of the D1 photosystem II reaction center protein is controlled by an endogenous circadian rhythm. Plant Physiol., 2002, 130, 2069-2075.

[63] Rintamäki, E.; Kettunen, R.; Aro, E.M. Differential D1 dephosphorylation in functional and photodamaged photosystem II centers Dephosphorylation is a prerequisite for degradation of damaged D1. J. Biol. Chem., 1996, 271, 14870-14875.

[64] Fristedt, R.; Willig, A.; Granath, P.; Crèvecoeur, M.; Rochaix, J.D.; Vener, A. V. Phosphorylation of photosystem II controls functional macroscopic folding of photosynthetic membranes in Arabidopsis. Plant Cell, 2009, 21, 3950-3964.

[65] Rochaix, J.-D.; Lemeille, S.; Shapiguzov, A.; Samol, I.; Fucile, G.; Willig, A.; Goldschmidt-Clermont, M. Protein kinases and phosphatases involved in the acclimation of the photosynthetic apparatus to a changing light environment. Philos. Trans. R. Soc. Lond. B Biol. Sci., 2012, 367, 3466-3474.

[66] Tikkanen, M; Aro E-M. Integrative regulatory network of plant thylakoid energy transduction. Trends Plant Sci., 2014, 19(1), 1017.

[67] Mehler, A. Studies on the reactions of illuminated chloroplasts 11 Stimulation on inhibition of the reaction with molecular oxygen. Arch. Biochem. Biophys., 1951, 34, 339-351.

[68] Takahashi, M.; Asada, K. Superoxide production in aprotic interior of chloroplast thylakoids. Arch. Biochem. Biophys., 1988, 267, 714-722.

[69] Asada, K. The water-water cycle as alternative photon and electron sinks. Philos. Trans. R. Soc. Lond. B Biol. Sci., 2000, 355, 14191431.

[70] Frank, F.; Houyoux, P.-A. The Mehler Reaction in Chlamydomonas During Photosynthetic Induction and Steady-State Photosynthesis in Wild-Type and in a Mitochondrial Mutant, In: Allen, J.F.; Gantt, E.; Golbeck, J.H.; Osmond, B. Eds., Photosynthesis. Energy from the Sun: 14th International Congress on Photosynthesis, Springer Netherlands, Dordrecht, 2008,: pp. 581-584.

[71] Ort, D.R.; Baker, N.R. A photoprotective role for $\mathrm{O}_{2}$ as an alternative electron sink in photosynthesis? Curr. Opin. Plant Biol., 2002, 5, 193-198.

[72] Driever, S.M.; Baker, N.R. The water-water cycle in leaves is not a major alternative electron sink for dissipation of excess excitation energy when $\mathrm{CO}_{2}$ assimilation is restricted. Plant Cell Environ., 2011, 34, 837-846.

[73] Shirao, M.; Kuroki, S.; Kaneko, K.; Kinjo, Y.; Tsuyama, M.; Förster, B.; Takahashi, S.; Badger, M.R. Gymnosperms Have Increased Capacity for Electron Leakage to Oxygen (Mehler and PTOX reactions) in Photosynthesis Compared with Angiosperms. Plant Cell Physiol., 2013, 54, 1152-1163.

[74] Michelet, L.; Krieger-Liszkay, A. Reactive oxygen intermediates produced by photosynthetic electron transport are enhanced in short-day grown plants. Biochim. Biophys. Acta, 2012, 1817, 13061313.

[75] Sang, M.; Xie, J.; Qin, X.-C.; Wang, W.-D.; Chen, X.-B.; Wang, K.-B.; Zhang, J.-P.; Li, L.-B.; Kuang, T.-Y. High-light induced superoxide radical formation in cytochrome b6f complex from 
Bryopsis corticulans as detected by EPR spectroscopy. $J$. Photochem. Photobiol. B, 2011, 102, 177-181.

[76] Pospíšil, P. Molecular mechanisms of production and scavenging of reactive oxygen species by photosystem II. Biochim. Biophys. Acta, 2012, 1817, 218-231.

[77] Foyer, C.H.; Bloom, A.J.; Queval, G.; Noctor, G. Photorespiratory metabolism: genes, mutants, energetics, and redox signaling. Ann. Rev. Plant Biol., 2009, 60, 455-484.

[78] Arató, A.; Bondarava, N.; Krieger-Liszkay, A. Production of reactive oxygen species in chloride- and calcium-depleted photosystem II and their involvement in photoinhibition. Biochim. Biophys. Acta, 2004, 1608, 171-180.

[79] Mubarakshina, M.M.; Ivanov, B.N. The production and scavenging of reactive oxygen species in the plastoquinone pool of chloroplast thylakoid membranes. Physiol. Plant., 2010, 140, 103-110.

[80] Miyake, C. Alternative electron flows (water-water cycle and cyclic electron flow around PSI) in photosynthesis: molecular mechanisms and physiological functions. Plant Cell Physiol., 2010, 51, 1951-1963.

[81] Dietz, K.-J. Peroxiredoxins in plants and cyanobacteria. Antioxid. Redox Signal., 2011, 15, 1129-1159.

[82] Noctor, G.; Gomez, L.; Vanacker, H.; Foyer, C.H. Interactions between biosynthesis, compartmentation and transport in the control of glutathione homeostasis and signalling. J. Exp. Bot., 2002, 53, 1283-1304.

[83] Smirnoff, N.; Conklin, P.L.; Loewus, F.A. Biosynthesis of ascorbic acid in plants: A Renaissance. Ann. Rev. Plant Physiol. Plant Mol. Biol., 2001, 52, 437-467.

[84] Ledford, H.K.; Chin, B.L.; Niyogi, K.K. Acclimation to singlet oxygen stress in Chlamydomonas reinhardtii. Eukaryotic Cell, 2007, 6, 919-930.

[85] Fischer, B.B.; Ledford, H.K.; Wakao, S.; Huang, S.G.; Casero, D.; Pellegrini, M.; Merchant, S.S.; Koller, A.; Eggen, R.I.L.; Niyogi, K.K. SINGLET OXYGEN RESISTANT 1 links reactive electrophile signaling to singlet oxygen acclimation in Chlamydomonas reinhardtii. Proc. Natl Acad. Sci. U.S.A., 2012, 109, E1302-E1311.

[86] Kruk, J.; Trebst, A. Plastoquinol as a singlet oxygen scavenger in photosystem II. Biochim. Biophys; Acta, 2008, 1777, 154-162.

[87] Bisby, R.H.; Morgan, C.G.; Hamblett, I.; Gorman, A.A. Quenching of singlet oxygen by trolox $\mathrm{C}$, ascorbate, and amino acids: Effects of pH and temperature. J. Phys. Chem. A, 1999, 103, 7454-7459.

[88] Krieger-Liszkay, A.; Trebst, A. Tocopherol is the scavenger of singlet oxygen produced by the triplet states of chlorophyll in the PSII reaction centre. J. Exp. Bot., 2006, 57, 1677-1684.

[89] Krieger-Liszkay, A.; Kós, P.B.; Hideg, E. Superoxide anion radicals generated by methylviologen in photosystem I damage photosystem II. Physiol. Plant., 2011, 142, 17-25.

[90] Sonoike, K. Photoinhibition of photosystem I. Physiol. Plant., 2011, 142, 56-64.

[91] Maxwell, K., Johnson, G.N. Chlorophyll fluorescence--a practical guide. J. Exp. Bot., 2000, 51, 659-68.

[92] Quick, W.P.; Stitt, M. An examination of factors contributing to non-photochemical quenching of chlorophyll fluorescence in barley leaves. Biochim. Biophys. Acta, 1989, 977, 287-296.

[93] Nilkens, M.; Kress, E.; Lambrev, P.; Miloslavina, Y.; Müller, M.; Holzwarth, A.R.; Jahns, P. Identification of a slowly inducible zeaxanthin-dependent component of non-photochemical quenching of chlorophyll fluorescence generated under steady-state conditions in Arabidopsis. Biochim. Biophys. Acta, 2010, 1797, 466-475.

[94] Li, Z.; Wakao, S.; Fischer, B.B.; Niyogi, K.K. Sensing and responding to excess light. Ann. Rev. Plant Biol., 2009, 60, 239260.

[95] Demmig-Adams, B.; Adams, W.W. The role of xanthophyll cycle carotenoids in the protection of photosynthesis. Trends Plant Sci., 1996, 1, 21-26.

[96] Niyogi, K.K.; Björkman, O.; Grossman, A.R. The roles of specific xanthophylls in photoprotection. Proc. Natl Acad. Sci. U.S.A., 1997, 94, 14162-14167.

[97] Niyogi, K.K.; Shih, C.; Soon Chow, W.; Pogson, B.J.; Dellapenna, D.; Björkman, O. Photoprotection in a zeaxanthin- and luteindeficient double mutant of Arabidopsis. Photosynth. Res., 2001, 67, 139-145.

[98] Amarnath, K.; Zaks, J.; Park, S.D.; Niyogi, K.K.; Fleming, G.R. Fluorescence lifetime snapshots reveal two rapidly reversible mechanisms of photoprotection in live cells of Chlamydomonas reinhardtii. Proc. Natl Acad. Sci. U.S.A., 2012, 109, 8405-8410.

[99] Li, X.P.; Björkman, O.; Shih, C.; Grossman, A R.; Rosenquist, M.; Jansson, S.; Niyogi, K.K. A pigment-binding protein essential for regulation of photosynthetic light harvesting. Nature, 2000, 403, 391-395

[100] Peers, G.; Truong, T.B.; Ostendorf, E.; Busch, A.; Elrad, D.; Grossman, A.R.; Hippler, M.; Niyogi, K.K. An ancient lightharvesting protein is critical for the regulation of algal photosynthesis. Nature, 2009, 462, 518-521.

[101] Bonente, G.; Ballottari, M.; Truong, T.B.; Morosinotto, T.; Ahn, T.K.; Fleming, G.R.; Niyogi, K.K.; Bassi, R. Analysis of LhcSR3, a protein essential for feedback de-excitation in the green alga Chlamydomonas reinhardtii. PLoS Biol., 2011, 9, e1000577.

[102] Niyogi, K.K.; Truong, T.B. Evolution of flexible nonphotochemical quenching mechanisms that regulate light harvesting in oxygenic photosynthesis. Curr. Opin. Plant Biol., 2013, 16, 307-314.

[103] Gerotto, C.; Morosinotto, T. Evolution of photoprotection mechanisms upon land colonization: evidences of PSBS dependent NPQ in late Streptophyte algae. Physiol. Plant., 2013, 19(1), 10-17.

[104] Alboresi, A.; Gerotto, C.; Giacometti, G.M; Bassi, R.; Morosinotto, T. Physcomitrella patens mutants affected on heat dissipation clarify the evolution of photoprotection mechanisms upon land colonization. Proc. Natl. Acad. Sci. U.S.A., 2010, 107, 11128 11133.

[105] Külheim, C.; Agren, J.; Jansson, S. Rapid regulation of light harvesting and plant fitness in the field. Science, 2002, 297, 91-93.

[106] Johnson, M.P.; Goral, T.K.; Duffy, C.D.P.; Brain, A.P.R.; Mullineaux, C.W.; Ruban, A.V. Photoprotective energy dissipation involves the reorganization of photosystem II light-harvesting complexes in the grana membranes of spinach chloroplasts. Plant Cell, 2011, 23, 1468-1479.

[107] Kanazawa, A.; Kramer, D.M. In vivo modulation of nonphotochemical exciton quenching (NPQ) by regulation of the chloroplast ATP synthase. Proc. Natl. Acad. Sci. U.S.A., 2002, 99, 12789-12794.

[108] Kohzuma, K.; Dal Bosco, C.; Meurer, J.; Kramer, D.M. Light- and Metabolism-Related Regulation of the Chloroplast ATP Synthase have Distinct Mechanisms and Functions. J. Biol. Chem., 2013 288, 13156-13163

[109] Niyogi, K.K. Safety valves for photosynthesis. Curr. Opin. Plant Biol., 2000, 3, 455-460.

[110] García-Plazaola, J.I.; Esteban, R.; Fernández-Marín, B.; Kranner, I.; Porcar-Castell, A. Thermal energy dissipation and xanthophyll cycles beyond the Arabidopsis model. Photosynth. Res., 2012, 113, 89-103.

[111] Ruban, A. V; Johnson, M.P.; Duffy, C.D.P. The photoprotective molecular switch in the photosystem II antenna. Biochim. Biophys. Acta, 2012, 1817, 167-181.

[112] Roach, T.; Krieger-Liszkay, A. The role of the PsbS protein in the protection of photosystems I and II against high light in Arabidopsis thaliana. Biochim. Biophys. Acta, 2012, 1817, 2158 2165.

[113] Ramel, F.; Birtic, S.; Ginies, C.; Soubigou-Taconnat, L.; Triantaphylidès, C.; Havaux, M. Carotenoid oxidation products are stress signals that mediate gene responses to singlet oxygen in plants. Proc. Natl. Acad. Sci. U.S.A., 2012, 109(14), 5535-5540.

[114] Fernández-Marín, B.; Balaguer, L.; Esteban, R.; Becerril, J.M.; García-Plazaola, J.I. Dark induction of the photoprotective xanthophyll cycle in response to dehydration. J. Plant Physiol., 2009, 166, 1734-1744.

[115] Ohad, I.; Raanan, H.; Keren, N.; Tchernov, D.; Kaplan, A. Lightinduced changes within photosystem II protects Microcoleus sp in biological desert sand crusts against excess light. PloS One, 2010, 5 , e11000.

[116] Heber, U.; Bilger, W.; Shuvalov, V.A. Thermal energy dissipation in reaction centres and in the antenna of photosystem II protects desiccated poikilohydric mosses against photo-oxidation. J. Exp. Bot., 2006, 57, 2993-3006.

[117] Faller, P.; Fufezan, C.; Rutherford, A.W. Side-Path Electron Donors: Cytochrome b 559, Chlorophyll $\mathrm{Z}$ and $\beta$-Carotene, In: Wydrzynski, T.J., Satoh, K., Freeman, J.A. Eds., Springer-Verlag, Berlin/Heidelberg, 2005, pp. 347-365. 
[118] Heber, U.; Bilger, W.; Türk, R.; Lange, O.L. Photoprotection of reaction centres in photosynthetic organisms: mechanisms of thermal energy dissipation in desiccated thalli of the lichen Lobaria pulmonaria. New Phytol., 2010, 185, 459-470.

[119] Havaux, M.; Dall'Osto, L.; Bassi, R. Zeaxanthin has enhanced antioxidant capacity with respect to all other xanthophylls in Arabidopsis leaves and functions independent of binding to PSII antennae. Plant Physiol., 2007, 145, 1506-1520.

[120] Baroli, I.; Do, A.D.; Yamane, T.; Niyogi, K.K. Zeaxanthin Accumulation in the Absence of a Functional Xanthophyll Cycle Protects Chlamydomonas reinhardtii from Photooxidative Stress. Plant Cell, 2003, 15, 992-1008.

[121] Dall'Osto, L.; Cazzaniga, S.; North, H.; Marion-Poll, A.; Bassi, R. The Arabidopsis aba4-1 mutant reveals a specific function for neoxanthin in protection against photooxidative stress. Plant Cell, 2007, 19, 1048-1064.

[122] Kirilovsky, D.; Kerfeld, C.A. The Orange Carotenoid Protein: a blue-green light photoactive protein. Photochem. Photobiol. Sci., 2013, 12, 1135-1143.

[123] Tikkanen, M.; Grieco, M.; Nurmi, M.; Rantala, M.; Suorsa, M.; Aro, E.-M. Regulation of the photosynthetic apparatus under fluctuating growth light. Philos. Trans. R. Soc. Lond. B Biol. Sci., 2012, 367, 3486-3493.

[124] Bellafiore, S.; Barneche, F.; Peltier, G.; Rochaix, J.-D. State transitions and light adaptation require chloroplast thylakoid protein kinase STN7. Nature, 2005, 433, 892-895.

[125] Pesaresi, P.; Pribil, M.; Wunder, T.; Leister, D. Dynamics of reversible protein phosphorylation in thylakoids of flowering plants: the roles of STN7, STN8 and TAP38. Biochim. Biophys. Acta, 2011, 1807, 887-896.

[126] Allen, J.F. Protein phosphorylation in regulation of photosynthesis. Biochim. Biophys. Acta, 1992, 1098, 275-335.

[127] Wollman, F.A. State transitions reveal the dynamics and exibility of the photosynthetic apparatus. EMBO J., 2001, 20, 3623-3630.

[128] Finazzi, G.; Furia, A.; Barbagallo, R.P.; Forti, G. State transitions, cyclic and linear electron transport and photophosphorylation in Chlamydomonas reinhardtii. Biochim. Biohys. Acta, 1999, 1413, 117-129.

[129] Takahashi, H.; Clowez, S.; Wollman, F.-A.; Vallon, O.; Rappaport, F. Cyclic electron flow is redox-controlled but independent of state transition. Nature Comm., 2013, 4, 1954.

[130] Tikhonov, A.N. pH-Dependent regulation of electron transport and ATP synthesis in chloroplasts. Photosynth. Res., 2013, 116(2-3), 511-534.

[131] Foyer, C.H.; Neukermans, J.; Queval, G.; Noctor, G.; Harbinson, J. Photosynthetic control of electron transport and the regulation of gene expression. J. Exp. Bot., 2012, 63, 1637-1661.

[132] Takizawa, K.; Cruz, J.A.; Kanazawa, A.; Kramer, D.M. The thylakoid proton motive force in vivo Quantitative, non-invasive probes, energetics, and regulatory consequences of light-induced pmf. Biochim. Biophys. Acta, 2007, 1767, 1233-1244.

[133] Schlodder, E.; Meyer, B. pH-dependence of oxygen evolution and reduction kinetics of photoxidized chlorophyll -AII (P680) in photosystem II particles from Synechococcus sp. Biochim. Biophys. Acta, 1987, 890, 23-31.

[134] Krieger, A.; Weis, E. The role of calcium in the pH-dependent control of Photosystem II. Photosynth. Res., 1993, 37, 117-130.

[135] Munekage, Y., Hojo, M.; Meurer, J.; Endo, T.; Tasaka, M.; Shikanai, T. PGR5 is involved in cyclic electron flow around photosystem I and is essential for photoprotection in Arabidopsis. Cell, 2002, 110, 361-371.

[136] Terashima, M.; Petroutsos, D.; Hüdig, M.; Tolstygina, I.; Trompelt, K.; Gäbelein, P.; Fufezan, C.; Kudla, J.; Weinl, S.; Finazzi, G.; Hippler, M. Calcium-dependent regulation of cyclic photosynthetic electron transfer by a CAS, ANR1, and PGRL1 complex. Proc. Natl. Acad. Sci. U.S.A., 2012, 109, 17717-17122.

[137] Hertle, A.P.; Blunder, T.; Wunder, T.; Pesaresi, P.; Pribil, M.; Armbruster, U.; Leister, D. PGRL1 is the elusive ferredoxinplastoquinone reductase in photosynthetic cyclic electron flow. Mol. Cell, 2013, 49, 511-523.

[138] Livingston, A.K.; Cruz, J.A.; Kohzuma, K.; Dhingra, A.; Kramer, D.M. An Arabidopsis mutant with high cyclic electron flow around photosystem I (hcef) involving the NADPH dehydrogenase complex. Plant Cell, 2010, 22, 221-233.
[139] Munekage, Y.N.; Genty, B.; Peltier, G. Effect of PGR5 impairment on photosynthesis and growth in Arabidopsis thaliana. Plant Cell Physiol., 2008, 49, 1688-1698.

[140] Johnson, G.N. Physiology of PSI cyclic electron transport in higher plants. Biochim. Biophys. Acta, 2011, 1807, 384-389.

[141] Golding, A.J.; Johnson, G.N. Down-regulation of linear and activation of cyclic electron transport during drought. Planta, 2003, 218, 107-114.

[142] Duanmu, D.; Miller, A.R.; Horken, K.M.; Weeks, D.P.; Spalding, M.H. Knockdown of limiting-CO2-induced gene HLA3 decreases $\mathrm{HCO}_{3}{ }^{-}$transport and photosynthetic $\mathrm{Ci}$ affinity in Chlamydomonas reinhardtii. Proc. Natl. Acad. Sci. U.S.A., 2009, 106, 5990-5995.

[143] Iwai, M.; Takizawa, K.; Tokutsu, R.; Okamuro, A.; Takahashi, Y.; Minagawa, J. Isolation of the elusive supercomplex that drives cyclic electron flow in photosynthesis. Nature, 2010, 464, 12101213.

[144] Jans, F.; Mignolet, E.; Houyoux, P.-A.; Cardol, P.; Ghysels, B.; Cuiné, S.; Cournac, L.; Peltier, G.; Remacle, C.; Franck, F. A type II $\mathrm{NAD}(\mathrm{P}) \mathrm{H}$ dehydrogenase mediates light-independent plastoquinone reduction in the chloroplast of Chlamydomonas. Proc. Natl. Acad. Sci. U.S.A., 2008, 105, 20546-20551.

[145] Joet, T.; Cournac, L.; Peltier, G.; Havaux, M. Cyclic Electron Flow around Photosystem I in C 3 Plants In vivo Control by the Redox State of Chloroplasts and Involvement of the NADHDehydrogenase Complex. Plant Physiol., 2002, 128, 760-769.

[146] Ifuku, K.; Endo, T.; Shikanai, T.; Aro, E.-M. Structure of the chloroplast NADH dehydrogenase-like complex: nomenclature for nuclear-encoded subunits. Plant Cell Physiol., 2011, 52, 15601568.

[147] Courteille, A.; Vesa, S.; Sanz-Barrio, R.; Cazalé, A.-C.; BecuweLinka, N.; Farran, I.; Havaux, M.; Rey, P.; Rumeau, D. Thioredoxin $\mathrm{m} 4$ controls photosynthetic alternative electron pathways in Arabidopsis. Plant Physiol., 2013, 161, 508-520.

[148] Joliot, P.; Johnson, G.N. Regulation of cyclic and linear electron flow in higher plants. Proc. Natl. Acad. Sci. U.S.A., 2011, 108, 13317-13322.

[149] Rumeau, D.; Peltier, G.; Cournac, L. Chlororespiration and cyclic electron flow around PSI during photosynthesis and plant stress response. Plant Cell Environ., 2007, 30, 1041-1051.

[150] Laureau, C.; De Paepe, R.; Latouche, G.; Moreno-Chacón, M.; Finazzi, G.; Kuntz, M.; Cornic, G.; Streb, P. Plastid terminal oxidase (PTOX) has the potential to act as a safety valve for excess excitation energy in the alpine plant species Ranunculus glacialis L. Plant Cell Environ., 2013, 36, 1296-1310.

[151] Cardol, P.; Bailleul, B.; Rappaport, F.; Derelle, E.; Béal, D.; Breyton, C.; Bailey, S.; Wollman, F.A., Grossman, A., Moreau, H., Finazzi, G. An original adaptation of photosynthesis in the marine green alga Ostreococcus. Proc. Natl. Acad. Sci. U.S.A., 2008, 105, 7881-7886.

[152] Streb, P.; Josse, E.-M.; Gallouet, E.; Baptist, F.; Kuntz, M.; Cornic, G. Evidence for alternative electron sinks to photosynthetic carbon assimilation in the high mountain plant species Ranunculus glacialis. Plant Cell Environ., 2005, 28, 1123-1135.

[153] Quiles, M.J. Stimulation of chlororespiration by heat and high light intensity in oat plants. Plant Cell Environ., 2006, 29, 1463-1470.

[154] Savitch, L. V.; Ivanov, A.G.; Krol, M.; Sprott, D.P.; Oquist, G.; Huner, N.P.A. Regulation of energy partitioning and alternative electron transport pathways during cold acclimation of lodgepole pine is oxygen dependent. Plant Cell Physiol., 2010, 51, 15551570 .

[155] Stepien, P.; Johnson, G.N. Contrasting responses of photosynthesis to salt stress in the glycophyte Arabidopsis and the halophyte thellungiella: role of the plastid terminal oxidase as an alternative electron sink. Plant Physiol., 2009, 149, 1154-1165.

[156] Houille-Vernes, L.; Rappaport, F.; Wollman, F.A.; Alric, J.; Johnson, X. Plastid terminal oxidase 2 (PTOX2) is the major oxidase involved in chlororespiration in Chlamydomonas. Proc. Natl. Acad. Sci. U.S.A., 2011, 108, 20820-20825.

[157] Rosso, D.; Ivanov, A.G.; Fu, A.; Geisler-Lee, J.; Hendrickson, L.; Geisler, M.; Stewart, G.; Krol, M.; Hurry, V.; Rodermel, S.R.; Maxwell, D.P.; Hüner, N.P. IMMUTANS does not act as a stressinduced safety valve in the protection of the photosynthetic apparatus of Arabidopsis during steady-state photosynthesis. Plant Physiol., 2006, 142, 574-585. 
[158] Heyno, E.; Gross, C.M.; Laureau, C.; Culcasi, M.; Pietri, S.; Krieger-Liszkay, A. Plastid alternative oxidase (PTOX) promotes oxidative stress when overexpressed in tobacco. J. Biol. Chem., 2009, 284, 31174-31180.

[159] Ahmad, N.; Michoux, F.; Nixon, P.J. Investigating the production of foreign membrane proteins in tobacco chloroplasts: expression of an algal plastid terminal oxidase. PloS One, 2012, 7, e41722.

[160] Trouillard, M.; Shahbazi, M.; Moyet, L.; Rappaport, F.; Joliot, P.; Kuntz, M.; Finazzi, G. Kinetic properties and physiological role of the plastoquinone terminal oxidase (PTOX) in a vascular plant. Biochim. Biophys. Acta, 2012, 1817, 2140-2148.

[161] Zhu, X.-G.; Ort, D.R.; Whitmarsh, J.; Long, S.P. The slow reversibility of photosystem II thermal energy dissipation on transfer from high to low light may cause large losses in carbon gain by crop canopies: a theoretical analysis. J. Exp. Bot., 2004, 55, 1167-1175.

Received: November 22, 2013

Revised: November 22, 2013

Accepted: March 16, 2014
[162] Murchie, E.H.; Niyogi, K.K. Manipulation of photoprotection to improve plant photosynthesis. Plant Physiol., 2011, 155, 86-92.

[163] Raven, J.A. The cost of photoinhibition. Physiol. Plant., 2011, 142 , 87-104.

[164] Guillemot, F.; Souquet, A.; Catros, S.; Guillotin, B.; Lopez, J.; Faucon, M.; Pippenger, B.; Bareille, R.; Rémy, M.; Bellance, S.; Chabassier, P.; Fricain, J.C.; Amédée, J. High-throughput laser printing of cells and biomaterials for tissue engineering. Acta Biomaterialia, 2010, 6, 2494-2500.

[165] Nagy, G.; Unnep, R.; Zsiros, O.; Tokutsu, R.; Takizawa, K.; Porcar, L.; Moyet, L.; Petroutsos, D.; Garab, G.; Finazzi, G.; Minagawa, J. Chloroplast remodeling during state transitions in Chlamydomonas reinhardtii as revealed by noninvasive techniques in vivo. Proc. Natl. Acad. Sci. USA. 2014 doi: 10.1073/ pnas.1322494111. 